\title{
Bast von Maulbeerbaumgewächsen für tragfähige Kunstwerke - von der wiederentdeckten Kultur der Rindenkleidung
}

\author{
Herwig ZaHORKA
}

\begin{abstract}
At fashion shows in Jakarta (Indonesia) well-known designers have presented models of colourful bark clothes which depict modern ethnic work of art. These bark clothes are skin friendly and attracted the attention of the audience.
\end{abstract}

\section{Zusammenfassung}

Bei Modenschauen in Jakarta (Indonesien) haben bekannte Designer auch farbenfrohe Entwürfe von Rindenkleidung ausgestellt. Sie stellen moderne ethnische Kunstwerke dar, sind hautfreundlich und erregen Aufsehen.

\section{Vorgeschichte}

Wahrscheinlich haben sich bereits Vormenschen, die in warmen Gebieten lebten, mit Rindenkleidung bedeckt. Gewebe aus Rinden gehören zu den ältesten Stoffen der Menschheit. Rindenkleider sind einfach herzustellen, strapazierfähig und hygienisch. Das Indonesische Museum für Textilien (Museum Tekstil) in Jakarta hat diese alte Mode aufgegriffen und vom 5. bis 29. April 2012 eine Sonderausstellung mit Rindenkleidern von verschiedenen Designern und aus verschiedenen ethnischen Kulturen zusammengestellt. Hierzu hat auch der Autor mit Stücken aus seiner persönlichen Sammlung beigetragen.

\section{Kleider aus Maulbeerbaumgewächsen}

In Süd- und Südostasien wird Rindenbast am häufigsten von vielen der mindestens 100 verschiedenen Artocarpus-Arten gewonnen. Dieser Gattung gehören auch die wichtigen Nutzpflanzen Jackfrucht- und Brotfruchtbaum an. Ebenso geeignet sind die zahlreichen FeigenArten (Ficus). Viele Ficus- und Artocarpus-Arten haben im tropischen Asien einen hohen Stellenwert, denn sie sind außer Faserlieferanten wichtige Medizinal- und Giftpflanzen.

Eine weitere beliebte Rindenbast liefernde Art ist der Papiermaulbeerbaum (Broussonetia

Abb. 1: Die von der harten Außenborke abgezogene Bastschicht muss flächendeckend ausgiebig auf einer Holzunterlage geklopft werden, damit sie dicht, weich und elastisch wird.

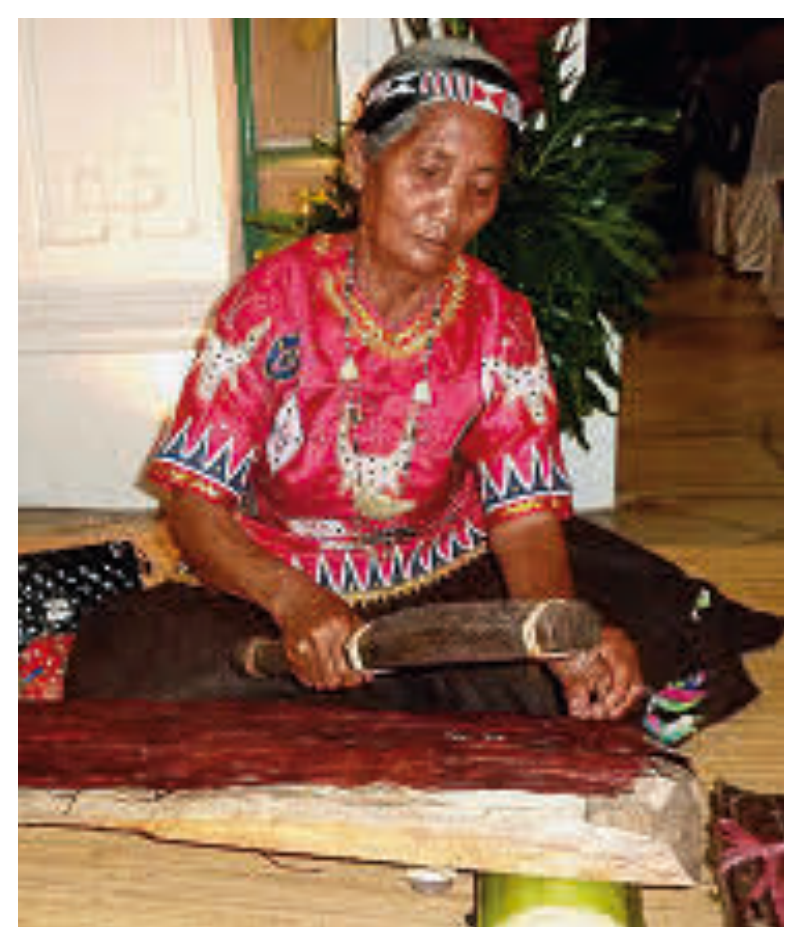

papyrifera), der ein besonders feines Fasergewebe liefert. Bei den Dayak in Borneo werden Kleidungsstücke auch aus dem Rindenbast von Antiaris toxicaria gefertigt. Dies ist ein extrem giftiger Baum, aus dessen Latex das hochwirksame Herzgift für die Blasrohrpfeile gewonnen wird. Auch sein Bast enthält dieses gefährliche Gift, das aber wasserlöslich ist und einfach aus den Fasern herausgewaschen werden kann.

\section{Gewinnung des Rindenbastes}

Baumstämme werden durch ein sekundäres Abschlussgewebe, die Borke, nach außen hin geschützt. Der unter der abgestorbenen, oft ver- 


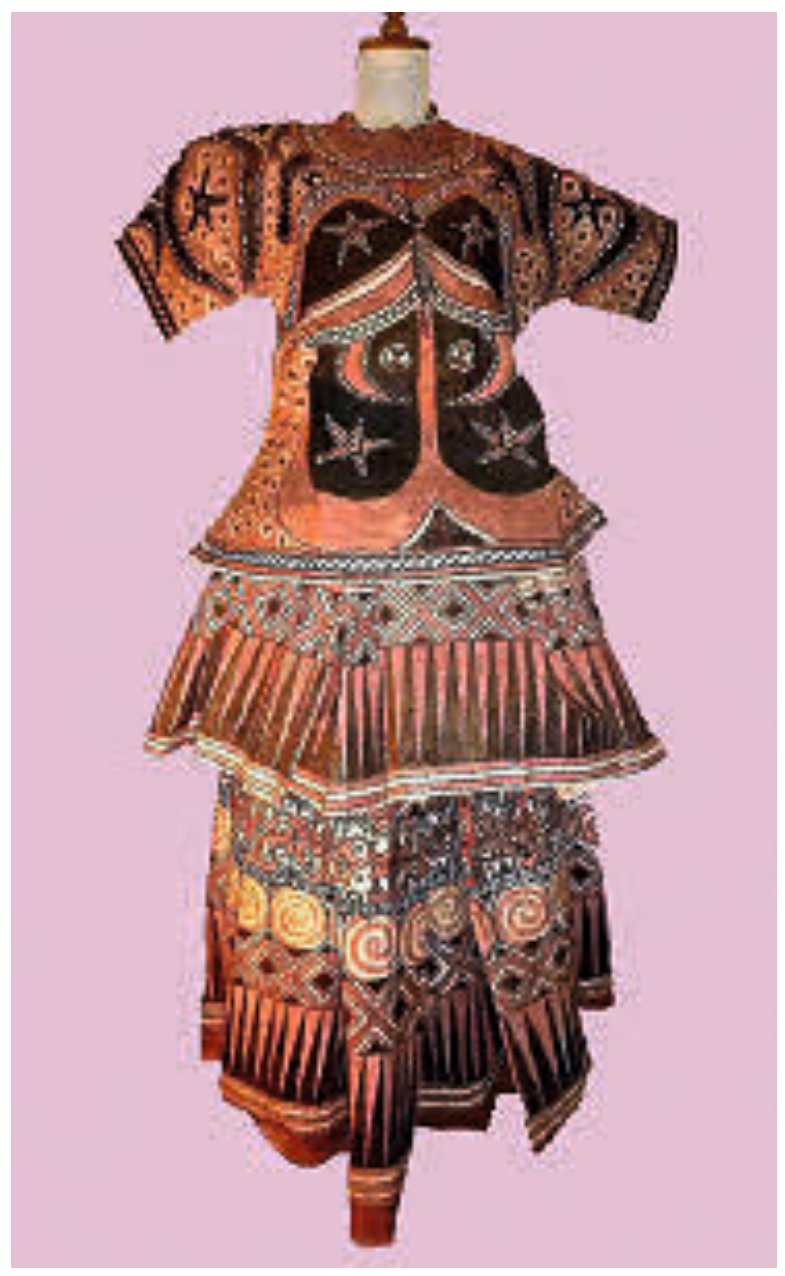

korkten Außenschicht liegende Bast ist oft sehr faserig und enthält Leitungsbahnen. In ihnen werden Fotosyntheseprodukte von den Blättern zu den Wurzeln transportiert. Aus dem Bast werden die Rindenkleider hergestellt. Zur Gewinnung der Fasern muss zunächst die Borke vom weiter innen liegenden Bildungsgewebe (Kambium) abgelöst werden. Anschließend kann die weiche Bastschicht von der harten Außenschicht abgezogen werden.

Dann folgt das aufwendige Klopfen der Bastbahnen. Als Unterlage wird Holz benutzt. Geklopft wird mir einem schweren, abgeflachten Holzknüppel oder mit Steinklopfern. Diese flächenhafte Bearbeitung verdichtet das Gewebe und macht es gleichzeitig weich und elastisch. Bei Benutzung einer runden Unterlage kann der Baststreifen rund geformt werden, wie es z. B. für einen Ärmel benötigt wird. Nach dieser Behandlung werden die Teile gewaschen und getrocknet.
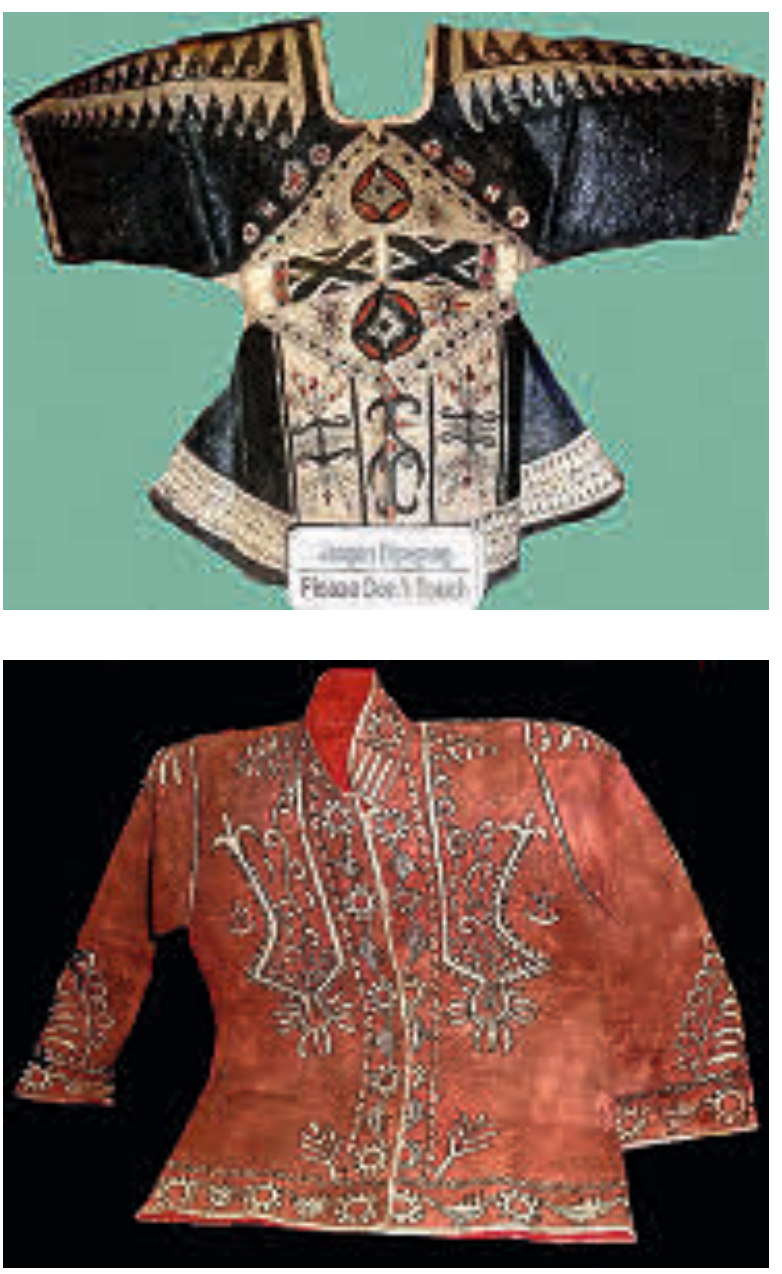

\section{Weiterverarbeitung}

Die Stoffbahnen können gebleicht oder gefärbt werden. Nachdem sie passend zugeschnitten sind, werden die Teile heute meist mit Nähmaschinen zusammengenäht. Oft werden Teile aus Leder, Metall, Knochen, Horn, Holz oder Glasperlen appliziert. Aus Pflanzen gewonnene Naturfarben werden bei der Bemalung von $\mathrm{Ri}$ tualkleidern nur noch in Stammesgebieten benutzt, ansonsten werden synthetische Farben verwendet. Gebrauchskleider können immer

Abb. 2 (links): Ein modernes, aufwendig bemaltes Rindenkleid für festliche Anlässe im Ethno-Stil.

Abb. 3 (oben rechts): Eine reichlich mit Stammessymbolen aus Zentral-Sulawesi bemalte Pracht-Bluse. Exponat im Textilmuseum Jakarta.

Abb. 4 (unten rechts): Eine moderne mit Symbolen bemalte Bluse mit Stehkragen, langen Ärmeln und Frontöffnung. 
wieder gewaschen werden. Rindenkleider sind sehr hautfreundlich und beugen mit ihren chemischen Eigenschaften Hautpilzinfektionen vor, die in den feuchten Tropen sehr häufig sind.

\section{Gründe, Rindenkleidung zu tragen}

Für Waldvölker sind Rindenkleider die optimale Bekleidung, weil sie leicht und billig herzustellen, waschbar und sehr strapazierfähig sind. Wer in der indonesischen Kolonialzeit nicht die Mittel hatte, europäische Kleidung zu erwerben, aber ebenso zivilisiert angezogen sein wollte und in Kleidern mit langen Ärmeln und in langen Hosen erscheinen wollte, fertigte sich einen vergleichbaren Anzug aus Rindenbast an. In der Zeit der japanischen Besetzung des Inselreiches (1942 bis 1945) und während des anschließenden Freiheitskampfes in Indonesien bis 1950 florierten Rindenkleider auch in den Städten, weil es keinen Import von Baumwollstoffen gab. Bei mehreren Stämmen auf den indonesischen „Außeninseln“ waren schmuckvolle Ritualkleider immer schon von besonderer Bedeutung. Diese Tendenz erfährt zur Zeit in den Städten eine Wiederbelebung bei Modenschauen mit Wettbewerben und Preisen für besondere Modelle. Bei manchen Modenschauen werden exquisite Rindenkleider von bekannten Designerinnen und Designern vorgeführt.
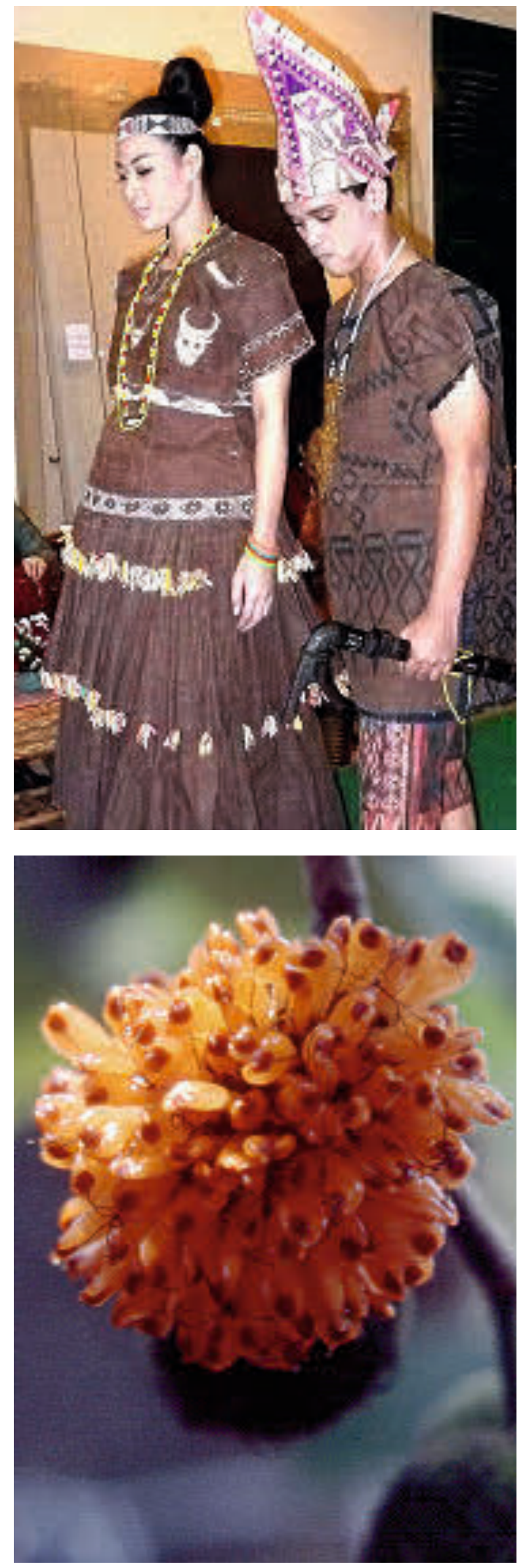

Abb. 5 (oben): Moderne Ethnokleidung aus Poso, Sulawesi, vorgeführt von Models aus der Großstadt.

Abb. 6 (unten): Fruchtstand des Papiermaulbeerbaumes. Aus der Rinde dieses Baumes werden Fasern gewonnen, die zu Textilien verarbeitet werden können. 